\title{
Lobar Hepatocellular Carcinoma with Ipsilateral Portal Vein Tumor Thrombosis Treated with Yttrium-90 Glass Microsphere Radioembolization: Preliminary Results
}

\author{
M. Pracht, ${ }^{1,2,3}$ J. Edeline, ${ }^{1,2,3}$ L. Lenoir, ${ }^{1,2,3}$ M. Latournerie, ${ }^{1}$ H. Mesbah, ${ }^{1}$ O. Audrain, ${ }^{1}$ \\ Y. Rolland, ${ }^{1}$ B. Clément, ${ }^{2,3}$ J. L. Raoul, ${ }^{4}$ E. Garin, ${ }^{1,2,3}$ and E. Boucher ${ }^{1,2,3}$ \\ ${ }^{1}$ Comprehensive Cancer Center Eugène Marquis, CS 44229, 35042 Rennes, France \\ ${ }^{2}$ University of Rennes 1, 35043 Rennes, France \\ ${ }^{3}$ INSERM U-991 Liver Metabolisms and Cancer, 35033 Rennes, France \\ ${ }^{4}$ Department of Digestive Oncology, Comprehensive Cancer Center Paoli Calmettes, 13273 Marseille, France
}

Correspondence should be addressed to O. Audrain; o.audrain@rennes.unicancer.fr

Received 22 August 2012; Revised 13 November 2012; Accepted 22 November 2012

Academic Editor: Zhi Dai

Copyright (C) 2013 M. Pracht et al. This is an open access article distributed under the Creative Commons Attribution License, which permits unrestricted use, distribution, and reproduction in any medium, provided the original work is properly cited.

\begin{abstract}
Portal vein tumor thrombosis (PVTT) is a common complication of hepatocellular carcinoma (HCC) and has a negative impact on prognosis. This characteristic feature led to the rationale of the present trial designed to assess the efficacy and the safety of yttrium90 glass-microsphere treatment for advanced-stage lobar HCC with ipsilateral PVTT. 18 patients with unresectable lobar HCC and ipsilateral PVTT were treated in our institution with ${ }^{90} \mathrm{Y}$-microS radioembolization. Patients were evaluated every 3 to 6 months for response, survival, and toxicity. Mean follow-up was 13.0 months (2.2-50.6). Outcomes were: complete response $(n=2)$, partial response $(n=13)$, stable disease $(n=1)$, and progressive disease $(n=2)$ giving a disease control rate of $88.9 \%$. Four patients were downstaged. Treating lobar hepatocellular carcinoma with ipsilateral portal vein thrombosis with yttrium-90 glass-microsphere radioembolization is safe and efficacious. Further clinical trials are warranted to confirm these results and to compare ${ }^{90} \mathrm{Y}$-microS with sorafenib, taking into account not only survival but also the possibility of secondary surgery for putative curative intention after downstaging.
\end{abstract}

\section{Introduction}

Hepatocellular carcinoma (HCC) is a common cancer with an estimated annual incidence of 600,000 worldwide [1]. During the disease course, $40 \%$ of patients will develop portal vein tumor thrombosis (PVTT) [2,3], a hallmark of advanced disease recognized as a poor prognosis factor by most classification systems: Barcelona Clinic Liver Cancer (BCLC) [4] and Cancer Liver Italian Program (CLIP) [5]. Patients with PVTT involving the portal trunk or main branch are considered to have advanced-stage disease (BCLC class C), independently of liver function or tumor size. Because of the risk of hepatic ischemia, the presence of PVTT complicates, or even contraindicates, locoregional treatments such as transarterial embolization/chemoembolization (TAE/TACE) designed to block arterial blood flow $[6,7]$. For these patients with advanced-stage HCC, palliative systemic treatments may be proposed [8]: sorafenib is currently the gold standard, even if debated, allowing significant improvement in time to progression and survival [9].

Considering the arterial hypervascularization associated with PVTT [10] and the radiosensitivity of HCC [11], radioisotopes would be a logical therapeutic option.

Recent retrospective analyses of single-center series have demonstrated an acceptable safety profile for new modalities of selective internal radiation therapy (SIRT) using radiolabeled glass microspheres, even in the presence of PVTT [12$18]$.

${ }^{90} \mathrm{Y}$-microspheres radioembolization is a recent concept in radiation therapy for HCC. Radiolabeled particles injected into the hepatic artery become trapped at the precapillary level where they emit potentially lethal internal radiation. 
This selective mechanism limits exposure to the surrounding normal parenchyma, thereby permitting higher dose delivery than with an external beam $[14,18]$.

We report here our experience with 18 patients with lobar HCC and ipsilateral intrahepatic PVTT given SIRT using yttrium-90 glass microspheres $\left({ }^{90} \mathrm{Y}\right.$-microS). These patients showing advanced diseases (PVTT) but involving only one lobe were treated with the intention to downstage their disease to a curative surgical treatment (transplantation or resection).

\section{Materials and Methods}

2.1. Patients and Tumors. From January 2007 to December 2010, 63 patients were treated in our center for HCC using intra-arterial ${ }^{90} \mathrm{Y}$-microS injections. Eighteen of these patients had lobar HCC with intrahepatic ipsilateral PVTT. All 18 patients had preserved hepatic function $(<2.5 \mathrm{XULN}$ total bilirubine, $<5$ XULN aminotransferases) and were in good general condition (WHO performance status score 0 or $1)$.

This retrospective study group included twelve men and six women, mean age 64.4 years, age range 44-77 years (Table 1). Histological and radiographic diagnoses were established in 16 patients, radiographic diagnosis alone in two [19]. No attempt was made to obtain a biopsy of the portal thrombus prior to treatment, but triphasic helical computed tomography demonstrated contrast uptake kinetics characteristic of PVTT observed in HCC: arterial enhancement and portal washout. The pathology classification was severe fibrosis in two patients; the other 16 had cirrhosis. The main underlying etiology was alcohol $(n=10)$. All tumors were unilobular with 7 showing multifocal and 3 infiltrating patterns. The PVTT was ipsilateral in all cases, branch thrombosis in 10, and intrahepatic trunk thrombosis in 8 , extending to lobular or segmental branches in 3 patients and to a hepatic vein in one. Serum alpha-fetoprotein level was below $400 \mathrm{ng} / \mathrm{mL}$ (parameter of the CLIP classification) in fourteen patients (normal in six), elevated in four $(>400 \mathrm{ng} / \mathrm{mL})$. For 13 patients, this protocol was the first-line treatment. Five patients had had one or more previous treatments: TACE $(n=3)$, sorafenib $(n=2)$, and radiofrequency $(n=2)$. Treatment with sorafenib was stopped at least one month before the SIRT procedure. One patient was treated with sorafenib during the procedure.

This retrospective study was approved by the institutional ethic board.

2.2. Treatment Planning. Pretreatment angiography and technetium-99 macroaggregated albumin single-photon emission computed tomography with CT coregistration (MAA SPECT/CT) were performed to assess gastrointestinal flow and lung shunting [20]. A glass-based device (TheraSphere, Ottawa, Canada) was used. The treatment by ${ }^{90} \mathrm{Y}$ glass microspheres was carried out as described by Salem and Thurston [21]. The activity to be injected $\left(A_{\text {inj }}\right)$ was classically calculated with the aim of delivering a dose $D$ of $120 \pm 20$ Gy to the volume to be treated (i.e., the injected liver, usually one lobe). This dose was calculated according to the
TABLE 1: Baseline characteristics $(n=18)$.

\begin{tabular}{|c|c|}
\hline Characteristic & Value \\
\hline Mean/median age (range) $(y)$ & $64.4 / 63.0(44-77)$ \\
\hline Sex ratio $\mathrm{M} / \mathrm{F}(n)$ & $12 / 6$ \\
\hline Cirrhosis/fibrosis $(n)$ & $16 / 2$ \\
\hline \multicolumn{2}{|l|}{ Main etiology $(n)$ : } \\
\hline $\begin{array}{l}\text { Alcohol/HCV/haemochromatosis/ } \\
\text { dysmetabolic syndrome }\end{array}$ & $10 / 4 / 3 / 1$ \\
\hline Child-Pugh score (n): A5-6/B7 & $13 / 5$ \\
\hline CLIP score $(n): 2 / 3 / 4$ & $11 / 5 / 2$ \\
\hline $\begin{array}{l}\text { Distribution }(n) \text { : } \\
\text { unifocal/multifocal/infiltrating }\end{array}$ & $8 / 7 / 3$ \\
\hline Mean/median (range) size $(\mathrm{cm})$ & $8 / 8.75(3-13)$ \\
\hline \multicolumn{2}{|l|}{ Portal vein tumour thrombosis $(n)$ : } \\
\hline Branch & 10 (8 right/2 left) \\
\hline Trunk (or trunk + branch) & 8 \\
\hline Tumour location $(n):$ right/left & $12 / 6$ \\
\hline $\begin{array}{l}\text { Mean/median (range): alpha-fetoprotein } \\
(\mathrm{ng} / \mathrm{mL})\end{array}$ & $7932 / 36.5(3-91000)$ \\
\hline
\end{tabular}

following formula, based on the Medical Internal Radiation Dose (MIRD) formalism, previously described and widely used $[12,16,21,22]$ :

$$
D_{(\mathrm{Gy})}=A_{\mathrm{inj}(\mathrm{GBq})} \cdot(1-S) \cdot 50 / W_{(\mathrm{Kg})},
$$

where " $S$ " is the lung shunt fraction, and " $W$ " is the weight of the injected liver.

2.3. Dosimetric Approach. SPECT acquisitions parameters were as follows: 32 projections, $180^{\circ}, 128 * 128,30$ s/projection (Symbia T2 gantry, Siemens, Germany). SPECT data were reconstructed using an iterative method (OSEM, 5 iterations, 8 subsets) with attenuation and scatter correction and then visualized with or without fusion with CT scan data.

The SPECT/CT quantitative uptake analysis of tumoral and nontumoral liver tissue was performed using the "volumetric analysis" software (Syngo workstation, Siemens). Briefly, this software allowed us to generate semiautomatically volume of interest (VOI) in the liver and tumor by means of an isocontour definition method. For each VOI, the threshold value was adjusted so that the isocontour of the distribution volume of MAA was superimposed on the fusion images that corresponded to the contours of the liver and tumor. These VOIs were then used to calculate the volumes of the liver and the tumor (expressed in $\mathrm{mL}$ ) in addition to the total activity (expressed in counts) contained in the liver $\left(\mathrm{CP}_{\mathrm{L}}\right)$ and tumor $\left(\mathrm{CP}_{\text {tum }}\right)$. Volume and total counts in the healthy liver $\left(\mathrm{CP}_{\mathrm{HL}}\right)$ were calculated by substracting liver and tumor parameters.

The dose absorbed in the tumour and in the healthy liver were then calculated using the classical formula:

$D_{(\mathrm{Gy})}=A_{(\mathrm{GBq})} \cdot 50 / W_{(\mathrm{Kg})}$, using:

(i) the activity $A_{\text {tum }}$ contained in the tumor $\left(A_{\text {tum }}=\right.$ $\left.A_{\text {inj(GBq) }} \cdot(1-S) \cdot \mathrm{CP}_{\text {tum }} /\left(\mathrm{CP}_{\text {tum }}+\mathrm{CP}_{\mathrm{HL}}\right)\right)$ and its weight for the tumoral dose; 
(ii) the activity $A_{\mathrm{HL}}$ contained in the healthy liver $\left(A_{\mathrm{HL}}=\right.$ $\left.A_{\text {inj(GBq) }} \cdot(1-S) \cdot \mathrm{CP}_{\mathrm{HL}} /\left(\mathrm{CP}_{\mathrm{HL}}+\mathrm{CP}_{\text {tum }}\right)\right)$ and its weight for the healthy liver dose.

2.4. Treatment Procedure. Within 2 weeks of the planning angiography study, the prescribed activity of ${ }^{90} \mathrm{Y}$ glass microspheres was administered by placing the tip of the delivery catheter in the same anatomic position as that used for the 99 mTc-MAA injection. Administration of ${ }^{90} \mathrm{Y}$ glass microspheres was always done selectively, in a lobar or segmental manner. Bremsstrahlung imaging was performed to confirm pretreatment MAA SPECT data for tumor targeting.

2.5. Evaluation and Followup. Clinical and biological evaluations were done after 1 and 4 weeks and then every 3 months. Analysis of efficacy was done at 3 and 6 months and then every 3 to 6 months by assessing European Association for the Study of the Liver (EASL) response criteria [19]: complete response (CR): absence of any enhancing tissue; partial response (PR): $>50 \%$ decrease in enhancing tissue; stable disease (SD): $<50 \%$ decrease in enhancing tissue. Progressive disease (PD) was defined as any increase in enhancement of the treated tumor that clinically would translate into additional locoregional therapy (i.e., repeat ${ }^{90} \mathrm{Y}$ ). Safety was assessed according to the Common Terminology Criteria for Adverse Events CTCAEv3.0 criteria [23]. Pathologic analysis of resected specimens in secondly operated patients was performed.

2.6. Statistics. The database was closed on October 1, 2011, the date at which all data were censored. Progression-free survival (PFS) was measured from the date of the first treatment until the date of progression in the treated liver. Overall survival (OS) was measured from the date of the first treatment until the date of death from any cause or of last followup. SAS software was used to determine overall survival and progression-free survival using the KaplanMeier method. The Kruskal-Wallis test was used to look for differences between controlled and noncontrolled tumors and univariate analysis applied the chi-square test with $P<$ 0.05 considered as statistically significant.

\section{Results and Discussion}

3.1. Patients and Treatments. The 18 patients received 21 treatments. Three patients received a second dose either because the first dosimetry was insufficient ( $n=2 ; 101$ and $106 \mathrm{~Gy}$, resp.) or because of an insufficient target ( $n=1$ multifocal tumor with 2 feeding arteries). Treatments characteristics are shown in Table 2.

The pulmonary shunt, determined by monitoring albumin macroaggregates, was minimal (mean 6.0\%, median $2.45 \%$, range $0-43.5 \%$ ) except in one patient $(43.5 \%$ in a patient with a voluminous intratumor arterioportal shunt). Injected activity varied from 1.31 to $7.51 \mathrm{GBq}$ (median $2.45 \mathrm{GBq})$. The lowest activity $(1.31 \mathrm{GBq})$ was delivered for the patient with the intratumor shunt in order to hold lung exposure below $30 \mathrm{~Gy}$ (estimated 28.5 Gy). The median dose delivered to the target volume was $117.8 \mathrm{~Gy}$, approaching the aim of $120 \pm 20 \mathrm{~Gy}[12,16,21,22]$. Two patients received an intensification of the treatment (increased injected activity of 30 and 50\%) regarding the large size of the lesions (10.6 and $13.0 \mathrm{~cm}$, resp.), their necrotic character and the presence of recently described, favorable predictive dosimetric parameters (26). Twelve patients showed albumin macroaggregates in their PVTT on the pretreatment technetium-99 macroaggregated albumin scanning (MAA SPECT/CT).

Tolerance was good for all patients. Adverse effects were grade 3 or less on the CTCAEv3.0 scale. Three patients (16.6\%) complained of abdominal, three (16.6\%) developed asthenia, and one (5.5\%) anorexia. Seven patients $(38.9 \%)$ developed transient liver dysfunction: 6 decompensations with edema and ascite (including 1 with infection); 3 of the 6 were Child-Pugh B patients and 1 hepatic encephalopathy. No deaths could be attributed to the treatment.

3.2. Response and Patient Survival Outcomes. Biological and radiological response assessments were accomplished at 3, 6, and 9 months for, respectively, 18, 17, and 14 patients.

Biological response was recorded in all 4 patients with an elevated AFP level $(>400 \mathrm{ng} / \mathrm{mL})$ with an AFP decline of more than $80 \%$. Patients outcome are shown in Table 3.

The disease control rate was $83.3 \%$ with 2 complete responses, 13 partial responses, and 1 stable disease. When considering these 16 controlled patients, 13 showed objective radiologic response for both tumor and PVTT. Partial patency of the portal vein was observed in eight patients and complete involution of the thrombus in three others. For 15 of the 18 patients $(83.3 \%)$, there was a change in the aspect of the thrombus after treatment: objective decrease in contrast uptake due to devascularization of the portal tumor buds. Among the twelve patients with albumin macroaggregates deposit in their PVTT, nine showed patency of the portal venous network. Two of them had complete involution of their PVTT (Figure 1).

The two patients who received an intensified treatment showed a partial response without any significant toxicity.

Mean followup was 13.0 months (range 2.2-50.6). Followup was less than 1 year for six patients; four of them were dead. Survival rates at 6 months and 1 year were $88.5 \pm$ $14.7 \%$ and $70.3 \pm 21.1 \%$, respectively. Median progressionfree survival was 11.0 months (in the treated liver) after treatment end (95\% CI: 8.0-16.5). Median overall survival was not reached (95\% CI, 9.0- $)$ ) (Figures 2 and 3). Seven patients $(38.8 \%)$ had died at study end; deaths occurred 2.2 to 15.7 months after the first treatment. Four of these seven patients died because of the progression of the previously treated disease.

At univariate analysis, there was a trend to significant difference $(P=0.07)$ between controlled and noncontrolled patients in term of median tumor absorbed dose (Table 2).

Downstaging allowed surgery in four patients (22\%). Two of them were downstaged to be within the transplantation criteria [19]; one had a liver transplantation but the second one refused it. They, respectively, showed a progression free survival and an overall survival of 50.6 and 50.6 and of 16.0 and 38.0 months. The two other patients did not meet the transplantation criteria but were eligible for surgical 
TABLE 2: Treatment characteristics.

\begin{tabular}{lr}
\hline Characteristic & \multicolumn{1}{c}{ Value } \\
\hline Selectivity of 90Y injection: whole liver/lobar/segmental & $0 / 17 / 1$ \\
Median (range) activity (GBq) & $2.5(1.31-7.51)$ \\
Median (range) dose to the target volume (Gy) & $117.8(80.1-164.1)$ \\
Median (range) dose to the nontumoral liver (Gy) & $75.5(26.5-114.5)$ \\
Median (range) dose to the lungs (Gy) & $3.8(0-28.5)$ \\
Median (range) dose to the tumour (Gy) & $261.1(114.5-393.9)$ \\
Median (range) pulmonary shunt fraction (\%) & $2.4(0-43.5)$ \\
Median (range) dose of controlled patients (complete response + partial response + stable disease) & $284.5(194.0-393.9)$ \\
Median (range) dose of nonresponders patients & $181.5(114.5-248.6)$ \\
\hline
\end{tabular}

TABle 3: Treatment outcomes $(n=18)$.

\begin{tabular}{|c|c|}
\hline Characteristics & Value \\
\hline Dead/alive $(n)$ & $7 / 11$ \\
\hline Response $(n) \mathrm{CR} / \mathrm{PR} / \mathrm{SD} / \mathrm{PD}$ & $2 / 13 / 1 / 2$ \\
\hline Objective response/disease control rate (\%) & $83.3 / 88.9 \%$ \\
\hline $\begin{array}{l}\text { Median (95\% CI) time to progression } \\
\text { (months) }\end{array}$ & $11.0(8.0-16.5)$ \\
\hline $\begin{array}{l}\text { Median ( } 95 \% \mathrm{CI}) \text { overall survival } \\
\text { (from date of treatment) }\end{array}$ & Not reached $(9.0-\infty)$ \\
\hline $\begin{array}{l}\text { Downstaging to surgery or transplantation } \\
\text { criteria }(n)\end{array}$ & $4 / 18$ \\
\hline Overall survival at 6 months ( $\%$ and $95 \% \mathrm{CI}$ ) & $88.5 \pm 14.7$ \\
\hline Overall survival at 1 year (\% and 95\% CI) & $70.3 \pm 21.1$ \\
\hline
\end{tabular}

resection. One had a right hepatectomy while the other was discovered a second HCC during the surgery that contraindicated the programmed hepatectomy. They respectively showed a progression free survival and an overall survival of 13.8 and 14.8 and of 10.5 and 12.5 months.

\section{Discussion}

PVTT is a poor prognostic factor for HCC. According to the BCLC classification [4], patients with PVT have advancedstage disease, limiting options for surgery and intra-arterial therapy. Systemic administration of sorafenib can yield significant improvement in survival: median 8.1 months versus 4.9 with placebo for BCLC C patients with macrovascular invasion [26]. Sorafenib cannot, however, be considered as a curative treatment since there have been no reported cases of downsizing. The objective response rate with sorafenib (such as with other kinase inhibitors or monoclonal antibodies) is very low, less than 3\% with the RECIST criteria.

Selective internal radiation therapy was developed in the 1990s for HCC with PVTT. ${ }^{90} \mathrm{Y}$ is a higher energy beta emitter (Beta max 2.2 versus $0.6 \mathrm{MeV}$ ) with a broad cytoxicity range [27]. Radiation protection is a minor problem with ${ }^{90} \mathrm{Y}$, a pure beta emitter, allowing day hospital protocols. High activity doses may also be delivered to the tumor: median $2.5 \mathrm{GBq}$ in our study with a maximum of $7.5 \mathrm{GBq}$. The efficacy of these selective internal radiation treatments has not been assessed in prospective comparative trials (versus TACE, for instance), but generally is considered comparable, with better tolerance for radioembolization [28]. Data published to date on the use of radioembolization for palliative purposes in HCC patients with PVTT have demonstrated a very high response rate (50-70\%) [29], especially if the new response criteria taking into account tumor vascularization are applied [30]. The safety profile appears to be similar to that observed in patients without PVTT, especially for the embolic risk. This is also the case for resin microspheres: a recent series had no cases of postembolization syndrome or of hepatic ischemia [13]. The expression "selective internal radiation therapy" should be preferred to the term "radioembolization" since the embolic effect is marginal so that microspheres are not to be contraindicated in patients with PVTT.

Our series confirmed the safety of this treatment, a further argument favoring its efficacy on the thrombosis. Using the EASL criteria, the tumor was controlled in $88.9 \%$ of our patients at three months [19]; the thrombosis regressed in the majority (11/18). This antitumor effect allowed downstaging to surgery in four patients (22\%). Pathology examination of the explant in the patient who underwent liver transplantation showed a major histological response in the tumor nodules (the largest exhibited a totally necrotic aspect). The survival rate $(88.5 \%$ at six months) was promising, even better than with sorafenib: $\mathrm{mPFS}=11.0$ in our series versus 4.1 months in the subgroup with macrovascular invasion of the SHARP trial [26]. Our results appear a little better than those previously published (Table 4) probably because this cohort is homogenous, containing only patients with lobar HCC and intrahepatic ipsilateral PVTT whereas patients in previously published studies showed indifferently lobar or bilobar HCC and extended PVTT (extrahepatic or bilateral). These results are, however, in agreement with those just published in a prospective phase 2 by Mazzaferro et al. [25] showing a disease control rate of $74.3 \%$, an mPFS of 7.0 (6.0-12.0), and an mOS of 13.0 (9.0-17.0) months.

Like for some of these studies, our results confirm that downstaging advanced HCC with PVTT is not an unrealistic objective. Indeed, allowing to $22 \%(4 / 18)$ of these patients a downstaging to a curative surgical stage is a very encouraging data in the context of the classical poor outcome of this disease. Concerning the 14 remaining patients, 11 showed an objective response but unfortunately insufficient for a secondary curative surgery (insufficient tumor size reduction 


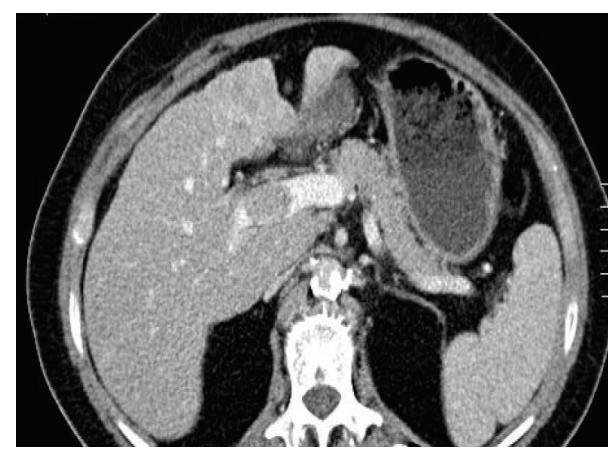

(a)

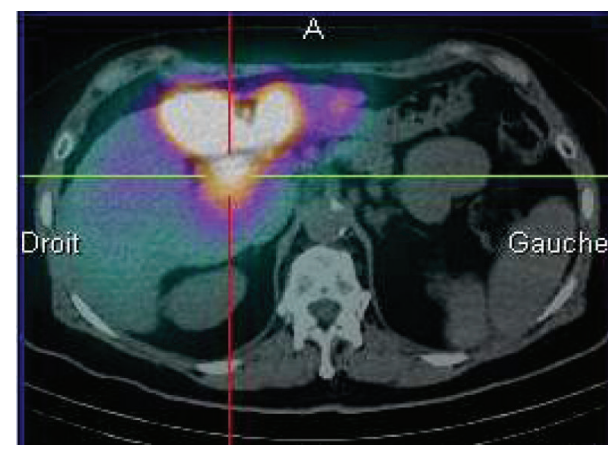

(c)

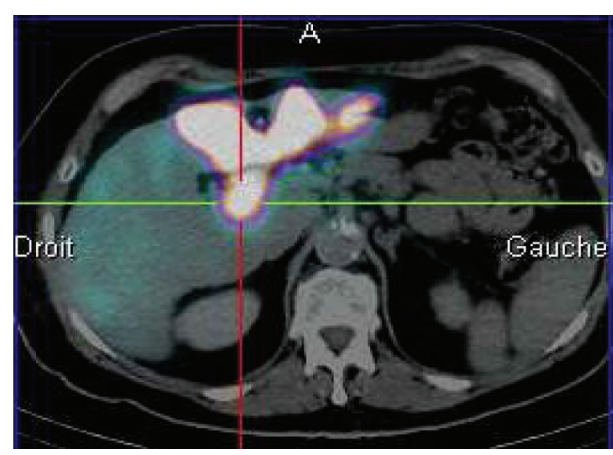

(b)

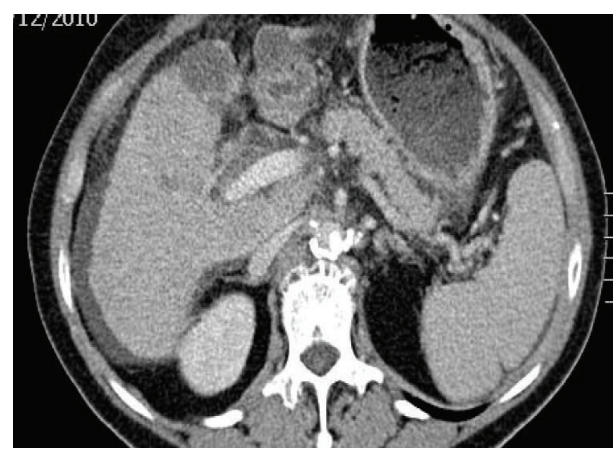

(d)

FIGURE 1: MAA SPECT/CT and CT scans showing implantation of microspheres in an PVTT and the involution of this PVTT after radioembolization: (a) Baseline CT scan, (b) MAA SPECT/CT showing a high MAA uptake in the PVTT, (c) Posttherapeutic Bremsstrahlung SPECT/CT after the injection of $4.5 \mathrm{GBq}$ of $90 \mathrm{Y}$-loaded glass microspheres: high uptake in the PVTT confirming the accurate implantation of microspheres in the PVTT, and (d) CT scan at 13 months.

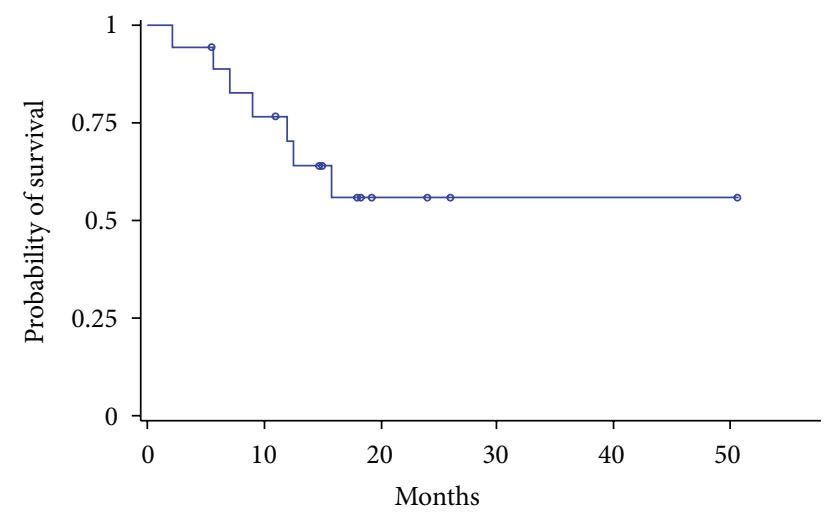

FIGURE 2: Kaplan-Meier analysis of overall survival (months): median overall survival not reached $(95 \% \mathrm{CI}, 9.0-\infty)$ aften mean followup of 13.0 months.

and/or incomplete involution of the PVTT). Only 3 patients did not respond to the treatment. For all $3,{ }^{90} \mathrm{Y}$ glass microspheres were a front-line treatment and their median TD was acceptable, higher than $114 \mathrm{~Gy}$. Two of these failures could be explained by tumor sizes higher than $10 \mathrm{~cm}$ and the last one could be due to an underlying advanced cirrhosis (ChildPugh B7), conditions known to be less favorable for SIRT.

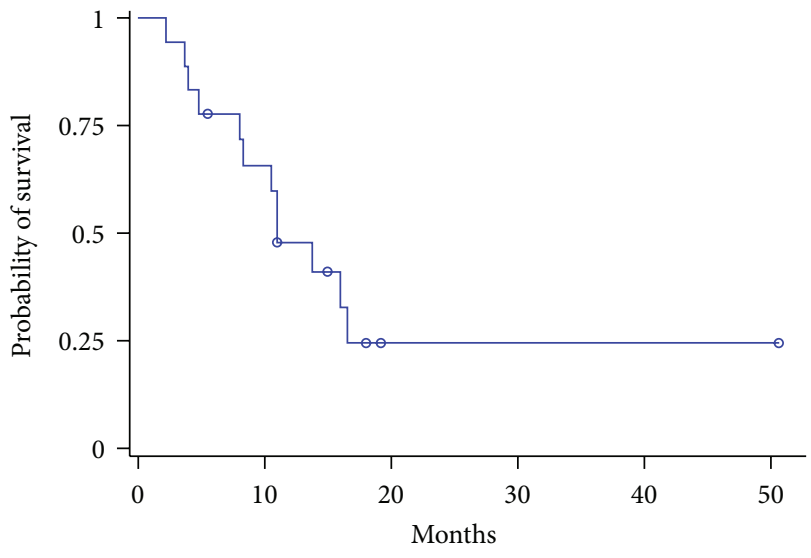

FIGURE 3: Kaplan-Meier analysis of progression-free survival (months): median progression-free survival was 11.0 months $(95 \%$ CI: 8.0-16.5).

Our interesting results do not seem influenced by the $27.7 \%(5 / 18)$ of patients previously treated. Indeed, even if all these patients showed a partial response on their liver tumor, 2 only of them showed partial patency of their portal vein tumor thrombosis. On the contrary, all these 5 patients showed adverse events (ascite), underscoring the risk of 
TABLE 4: Published studies on the treatment of HCC with PVTT with yttrium-90.

\begin{tabular}{|c|c|c|c|c|c|}
\hline $\begin{array}{l}\text { Study } \\
\text { (author/year/microspheres } \\
\text { type/reference) }\end{array}$ & $\begin{array}{c}\text { PVTT } \\
\text { population/total } \\
\text { population }\end{array}$ & $\begin{array}{c}\text { 6-month } \\
\text { survival (\%) }\end{array}$ & $\begin{array}{c}\text { Disease Control rate at } \\
X \text { months }(\%)\end{array}$ & $\begin{array}{l}\text { Median OS } \\
\text { (months) }\end{array}$ & $\begin{array}{l}\text { Median PFS } \\
\text { (months) }\end{array}$ \\
\hline Salem et al., 2004: glass [15] & $n=15 / 15$ & 53 & - & $\begin{array}{c}7.1 \\
(4.1-13.9)\end{array}$ & - \\
\hline $\begin{array}{l}\text { Woodall et al., 2009: glass } \\
{[18]}\end{array}$ & $n=15 / 52$ & - & - & 3.2 & - \\
\hline Kulik et al., 2008: glass [14] & $n=37 / 108$ & - & - & $\begin{array}{c}\text { Branch } \\
\text { PVTT: } 9.9(7.1-15.7) \\
\text { Main } \\
\text { PVTT: } 4.4(2.9-7.4)\end{array}$ & - \\
\hline $\begin{array}{l}\text { Tsai et al., 2010: glass and } \\
\text { resin [17] }\end{array}$ & $\begin{array}{c}n=22 / 22 \\
15 \text { evaluable }\end{array}$ & - & $\begin{array}{l}\text { 2-3 months : } 58 \\
\text { (RECIST) }\end{array}$ & 7.0 & - \\
\hline $\begin{array}{l}\text { Iñarrairaegui et al., 2010: } \\
\text { resin } \\
{[13]}\end{array}$ & $n=25 / 25$ & 64 & $\begin{array}{l}2 \text { months: } 66.7 \text { and } \\
6 \text { months: } 50 \text { (RECIST) }\end{array}$ & $\begin{array}{c}10.0 \\
(6.6-13.3)\end{array}$ & - \\
\hline $\begin{array}{l}\text { Hilgard et al., 2010: glass } \\
\text { [12] }\end{array}$ & $n=33 / 108$ & $\begin{array}{c}65 \\
(95 \% \mathrm{CI} \\
46-92 \%)\end{array}$ & $\begin{array}{c}3 \text { months: } 90 \text { (RECIST) } \\
94 \text { (EASL) }\end{array}$ & $10.0(6.0-\infty)$ & $8.0(5.9-\infty)$ \\
\hline $\begin{array}{l}\text { Salem et al., 2010: glass } \\
{[16]}\end{array}$ & $\begin{array}{c}n=92 / 291 \\
(35 \text { Child } A \text { and } 57 \\
\text { Child } B)\end{array}$ & - & $\begin{array}{l}\text { 2-3 months: } 50 \text { Child A } \\
\text { and } 32 \text { Child B (EASL) }\end{array}$ & $\begin{array}{c}10.4(7.2-16.6) \text { Child A } \\
5.6(4.5-6.7) \text { Child B }\end{array}$ & $\begin{array}{l}5.6(2.3-7.6) \text { Child A } \\
5.9(4.2-7.9) \text { Child B }\end{array}$ \\
\hline $\begin{array}{l}\text { Sangro et al., 2011: resin } \\
{[24]}\end{array}$ & $\begin{array}{c}n=76 / 325 \\
\text { (branch + main) }\end{array}$ & - & 3 months: $88.9 \%$ (EASL) & $\begin{array}{c}10.2 \\
(7.7-11.8)\end{array}$ & - \\
\hline \multicolumn{6}{|c|}{ Mazzaferro et al., 2012: glass } \\
\hline 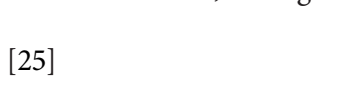 & $\begin{array}{c}n=35 / 52 \\
\text { (branch + main) }\end{array}$ & - & 3 months: 74.3 (EASL) & $\begin{array}{c}13.0 \\
(9.0-17.0)\end{array}$ & $\begin{array}{c}7.0 \\
(6.0-12.0)\end{array}$ \\
\hline
\end{tabular}

worse tolerance in case of pretreated tumors, especially after chemoembolization or large liver resections.

Regarding tumoral dosimetry, this study brings an interesting result as controlled lesions had higher dosimetry with a median dose to the tumor 284.5 Gy (194-393.9). However, the median tumor absorbed dose cannot in this small cohort be hold as a predictive factor of tumor response despite a trend to significance $(P=0.07)$ probably because a lack of power. This point needs to be highlighted in the next future as MAA SPECT/CT-based dosimetry results are available after the diagnostic angiography and before treatment and we will further explore it by continuing publishing the data of our patients showing lobar HCC with ipsilateral PVVT. It seems that to achieve an objective response, a sufficient activity of ${ }^{90} \mathrm{Y}$-microspheres needs to be injected. This kind of dose/response correlation has already been described by Ho et al. in 1996 [22] in the classical partition model. In this model, tumoral dosimetry (and tumoral activity) was evaluated using a tumor-to-nontumor uptake ratio evaluated by SPECT and not a direct calculation of the tumoral activity as we proposed here. The accuracy of this partitional model was not optimal (37.5\% of response if the tumoral dose was higher than 225 Gy and $10.3 \%$ if it was below this value) and tumoral dosimetry has not yet been proposed for the treatment planning (i.e., for the calculation of the activity to be injected). Our results may change this point in the next future. Indeed, we recently published preliminary results on $36 \mathrm{HCC}$ patients confirming this close dose response correlation [31]: a threshold dose of $205 \mathrm{~Gy}$ was predictive of the response with a sensitivity of $100 \%$, a specificity of $66 \%$, and an accuracy of $91 \%$ (only 3 nonresponders above $205 \mathrm{~Gy}$ on 36 ). Another confirmation has been brought by Chiesa et al. [32] who founded a median dose of the responding lesion of $431 \mathrm{~Gy}$ as against only $199 \mathrm{~Gy}$ for the nonresponding lesion $(P<0.0001)$. The tumoral dosimetry may now be shown not only as a part of the treatment planning but also as a tool to optimize the effectiveness of ${ }^{90}$ Y-microspheres radioembolization.

One of the major drawbacks of the present study is its retrospective design and the lack of control group. Systemic therapy with sorafenib was not started at the same time after ${ }^{90} \mathrm{Y}$ treatment in all patients who showed progressive disease, and this may have influenced overall survival. Finally, the small number of patients did not allow the calculation of significant difference in median tumor absorbed dose between controlled and noncontrolled tumors.

Based on the results of the present study, it appears that ${ }^{90} \mathrm{Y}$ radioembolization in patients with unilobar HCC and an ipsilateral intrahepatic PVTT confirmed the safety and antitumor efficacy of this therapeutic option in this population with an unfavorable prognosis with more than $20 \%$ of patients downstaged to a curative approach. Moreover, this study hypothesized a predictive value of the MAA SPECT/CT-based dosimetry on tumor response. Dosimetric 
optimizations could lead in the future to significant improvements of ${ }^{90} \mathrm{Y}$ radioembolization efficacy.

In light of our findings, a randomized trial would be useful in this population to compare ${ }^{90} \mathrm{Y}$ radioembolization versus sorafenib alone. In addition to overall survival, the trial should consider secondary curative surgery after downsizing as a main outcome criterion, similar to studies on liver metastases from colorectal adenocarcinoma [33]. There should, however, be some limits on inclusion: lobar HCC, ipsilateral branch or intrahepatic trunk PVTT and an appropriate liver function. Patients with bilateral thrombi or extension to the extrahepatic trunk would be poor indications due to the unfavorable benefit-risk ratio.

\section{Conflict of Interests}

E. Garin is a consultant for Nordion SA, J. L. Raoul is a consultant for Nordion SA and Bayer Pharmaceutical.

\section{References}

[1] D. M. Parkin, F. Bray, J. Ferlay, and P. Pisani, "Global cancer statistics, 2002,” CA Cancer Journal for Clinicians, vol. 55, no. 2, pp. 74-108, 2005.

[2] M. Pirisi, C. Avellini, C. Fabris et al., "Portal vein thrombosis in hepatocellular carcinoma: age and sex distribution in an autopsy study," Journal of Cancer Research and Clinical Oncology, vol. 124, no. 7, pp. 397-400, 1998.

[3] P. Tandon and G. Garcia-Tsao, "Prognostic indicators in hepatocellular carcinoma: a systematic review of 72 studies," Liver International, vol. 29, no. 4, pp. 502-510, 2009.

[4] J. M. Llovet, C. Brú, and J. Bruix, "Prognosis of hepatocellular carcinoma: the BCLC staging classification," Seminars in Liver Disease, vol. 19, no. 3, pp. 329-338, 1999.

[5] F. Perrone, "Prospective validation of the CLIP score: a new prognostic system for patients with cirrhosis and hepatocellular carcinoma. The Cancer of the Liver Italian Program (CLIP) Investigators," Hepatology, vol. 31, no. 4, pp. 840-845, 2000.

[6] J. L. Raoul, B. Sangro, A. Forner et al., "Evolving strategies for the management of intermediate-stage hepatocellular carcinoma: available evidence and expert opinion on the use of transarterial chemoembolization," Cancer Treatment Reviews, vol. 37, no. 3, pp. 212-220, 2011.

[7] Z. Sun, G. Li, X. Ai et al., "Hepatic and biliary damage after transarterial chemoembolization for malignant hepatic tumors: incidence, diagnosis, treatment, outcome and mechanism," Critical Reviews in Oncology/Hematology, vol. 79, no. 2, pp. 164174, 2011.

[8] J. M. Llovet, J. Bustamante, A. Castells et al., "Natural history of untreated nonsurgical hepatocellular carcinoma: rationale for the design and evaluation of therapeutic trials," Hepatology, vol. 29, no. 1, pp. 62-67, 1999.

[9] J. M. Llovet, S. Ricci, V. Mazzaferro et al., "Sorafenib in advanced hepatocellular carcinoma," The New England Journal of Medicine, vol. 359, no. 4, pp. 378-390, 2008.

[10] P. Sorrentino, L. Tarantino, S. D’Angelo et al., "Validation of an extension of the international non-invasive criteria for the diagnosis of hepatocellular carcinoma to the characterization of macroscopic portal vein thrombosis," Journal of Gastroenterology and Hepatology, vol. 26, no. 4, pp. 669-677, 2011.
[11] J. L. Raoul, D. Guyader, J. F. Bretagne et al., "Randomized controlled trial for hepatocellular carcinoma with portal vein thrombosis: intra-arterial iodine-131-iodized oil versus medical support," Journal of Nuclear Medicine, vol. 35, no. 11, pp. 17821787, 1994.

[12] P. Hilgard, M. Hamami, A. E. Fouly et al., "Radioembolization with yttrium-90 glass microspheres in hepatocellular carcinoma: european experience on safety and long-term survival," Hepatology, vol. 52, no. 5, pp. 1741-1749, 2010.

[13] M. Iñarrairaegui, K. G. Thurston, J. I. Bilbao et al., "Radioembolization with use of yttrium-90 resin microspheres in patients with hepatocellular carcinoma and portal vein thrombosis," Journal of Vascular and Interventional Radiology, vol. 21, no. 8, pp. 1205-1212, 2010.

[14] L. M. Kulik, B. I. Carr, M. F. Mulcahy et al., "Safety and efficacy of $90 \mathrm{Y}$ radiotherapy for hepatocellular carcinoma with and without portal vein thrombosis," Hepatology, vol. 47, no. 1, pp. 71-81, 2008.

[15] R. Salem, R. Lewandowski, C. Roberts et al., "Use of Yttrium90 glass microspheres (therasphere) for the treatment of unresectable hepatocellular carcinoma in patients with portal vein thrombosis," Journal of Vascular and Interventional Radiology, vol. 15, no. 4, pp. 335-345, 2004.

[16] R. Salem, R. J. Lewandowski, M. F. Mulcahy et al., "Radioembolization for hepatocellular carcinoma using Yttrium-90 microspheres: a comprehensive report of long-term outcomes," Gastroenterology, vol. 138, no. 1, pp. 52-64, 2010.

[17] A. L. Tsai, C. T. Burke, A. S. Kennedy et al., "Use of Yttrium-90 microspheres in patients with advanced hepatocellular carcinoma and portal vein thrombosis," Journal of Vascular and Interventional Radiology, vol. 21, no. 9, pp. 1377-1384, 2010.

[18] C. E. Woodall, C. R. Scoggins, S. F. Ellis et al., "Is selective internal radioembolization safe and effective for patients with inoperable hepatocellular carcinoma and venous thrombosis?" Journal of the American College of Surgeons, vol. 208, no. 3, pp. 375382, 2009.

[19] J. Bruix, M. Sherman, J. M. Llovet et al., "Clinical management of hepatocellular carcinoma: conclusions of the barcelona-2000 EASL conference," Journal of Hepatology, vol. 35, no. 3, pp. 421430, 2001.

[20] M. E. Hamami, T. D. Poeppel, S. Müller et al., "SPECT/CT with99mTc-MAA in radioembolization with90Y microspheres in patients with hepatocellular cancer," Journal of Nuclear Medicine, vol. 50, no. 5, pp. 688-692, 2009.

[21] R. Salem and K. G. Thurston, "Radioembolization with 90yttrium microspheres: a state-of-the-art brachytherapy treatment for primary and secondary liver malignancies: part 2: special topics," Journal of Vascular and Interventional Radiology, vol. 17, no. 9, pp. 1425-1439, 2006.

[22] S. Ho, W. Y. Lau, T. W. T. Leung et al., "Partition model for estimating radiation doses from yttrium-90 microspheres in treating hepatic tumours," European Journal of Nuclear Medicine, vol. 23, no. 8, pp. 947-952, 1996.

[23] A. Trotti, A. D. Colevas, A. Setser et al., "CTCAE v3.0: development of a comprehensive grading system for the adverse effects of cancer treatment," Seminars in Radiation Oncology, vol. 13, no. 3, pp. 176-181, 2003.

[24] B. Sangro, L. Carpanese, R. Cianni et al., "Survival after yttrium-90 resin microsphere radioembolization of hepatocellular carcinoma across Barcelona clinic liver cancer stages: a European evaluation," Hepatology, vol. 54, no. 3, pp. 868-878, 2011. 
[25] V. Mazzaferro, C. Sposito, S. Bhoori et al., "Yttrium(90) radioembolization for intermediate-advanced hepatocarcinoma: a phase II study," Hepatology. In Press.

[26] J. Bruix, A. Cheng, Y. Kang et al., "Effect of macroscopic vascular invasion (MVI), extrahepatic spread (EHS), and ECOG performance status (ECOG PS) on outcome in patients with advanced hepatocellular carcinoma (HCC) treated with sorafenib: analysis of two phase III, randomized, double-blind trials," Journal of Clinical Oncology, vol. 15, Supplement, abstract 4580, 2011.

[27] J. L. Raoul, E. Boucher, Y. Rolland, and E. Garin, “Treatment of hepatocellular carcinoma with intra-arterial injection of radionuclides," Nature Reviews Gastroenterology and Hepatology, vol. 7, no. 1, pp. 41-49, 2010.

[28] R. Salem, R. J. Lewandowski, L. Kulik et al., "Radioembolization results in longer time-to-progression and reduced toxicity compared with chemoembolization in patients with hepatocellular carcinoma," Gastroenterology, vol. 140, no. 2, pp. 497-507, 2011.

[29] S. M. Ibrahim, R. J. Lewandowski, K. T. Sato et al., "Radioembolization for the treatment of unresectable hepatocellular carcinoma: a clinical review," World Journal of Gastroenterology, vol. 14, no. 11, pp. 1664-1669, 2008.

[30] R. Lencioni and J. M. Llovet, "Modified recist (mRECIST) assessment for hepatocellular carcinoma," Seminars in Liver Disease, vol. 30, no. 1, pp. 52-60, 2010.

[31] E. Garin, L. Lenoir, Y. Rolland et al., "Dosimetry based on 99mTc-macroaggregated albumin SPECT/CT accurately predicts tumor response and survival in hepatocellular carcinoma patients treated with 90Y-loaded glass microspheres: preliminary results," Journal of Nuclear Medicine, vol. 52, no. 2, pp. 255263, 2012.

[32] C. Chiesa, M. Maccauro, R. Romito et al., "Need, feasibility and convenience of dosimetric treatment planning in liver selective internal radiation therapy with (90)Y microspheres: the experience of the National Cancer Institute of Milan," Quarterly Journal of Nuclear Medicine and Molecular Imaging, vol. 55, no. 2, pp. 168-197, 2011.

[33] R. D. Timmerman, C. S. Bizekis, H. I. Pass et al., "Local surgical, ablative, and radiation treatment of metastases," CA Cancer Journal for Clinicians, vol. 59, no. 3, pp. 145-170, 2009. 


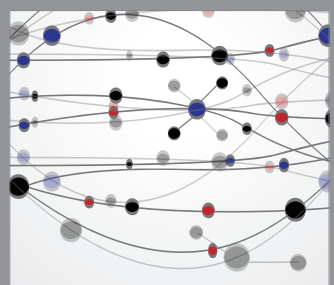

The Scientific World Journal
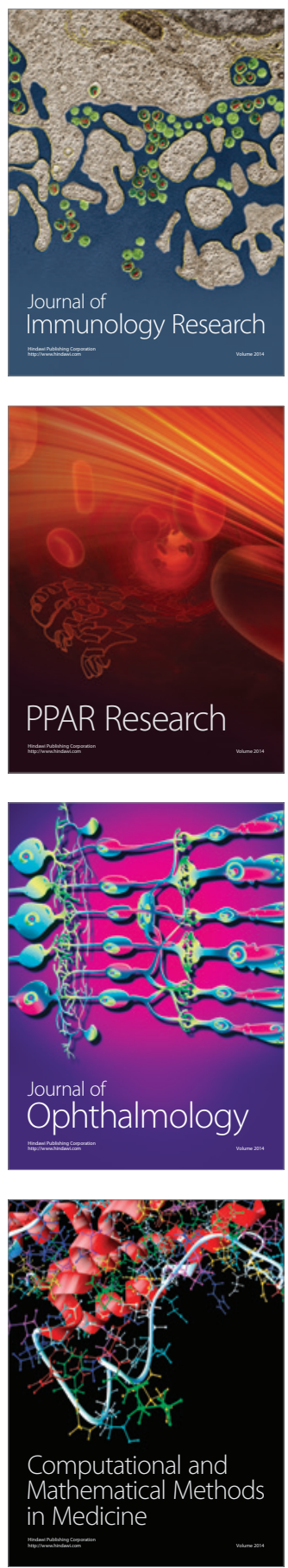

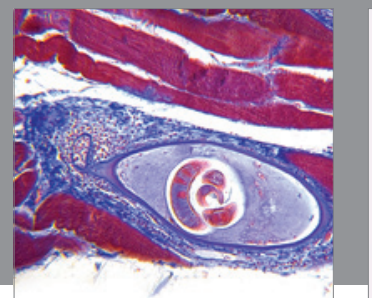

Gastroenterology

Research and Practice
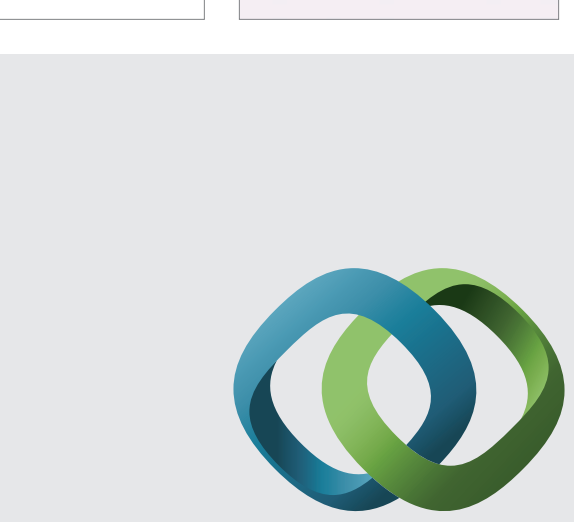

\section{Hindawi}

Submit your manuscripts at

http://www.hindawi.com
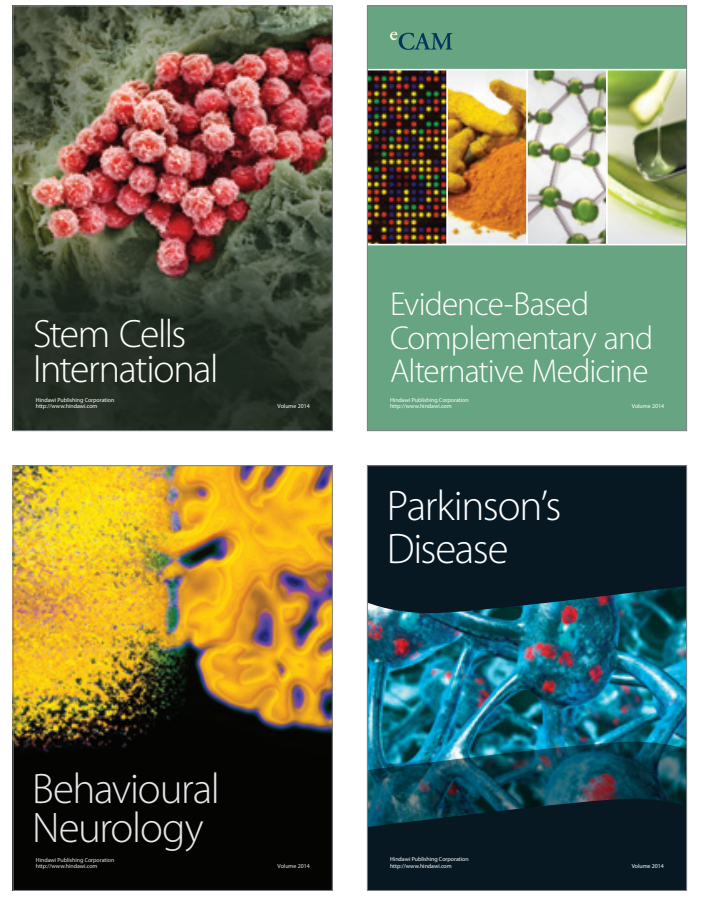
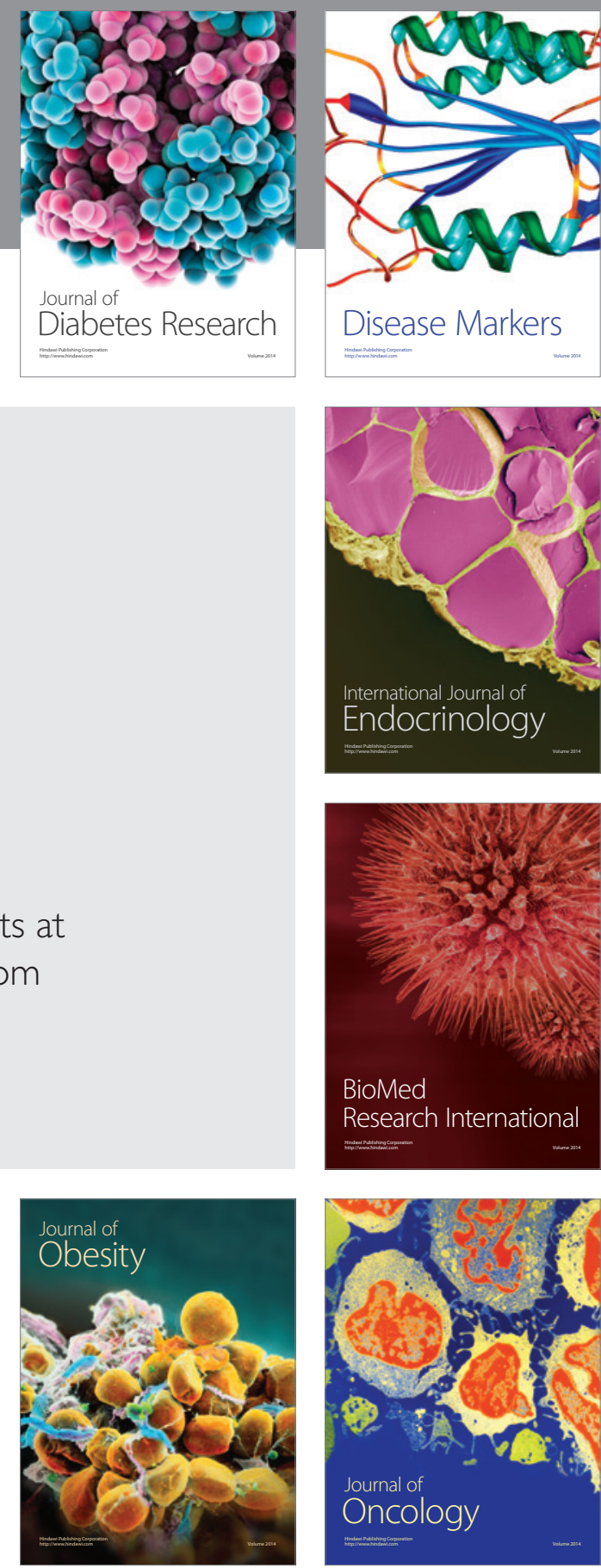

Disease Markers
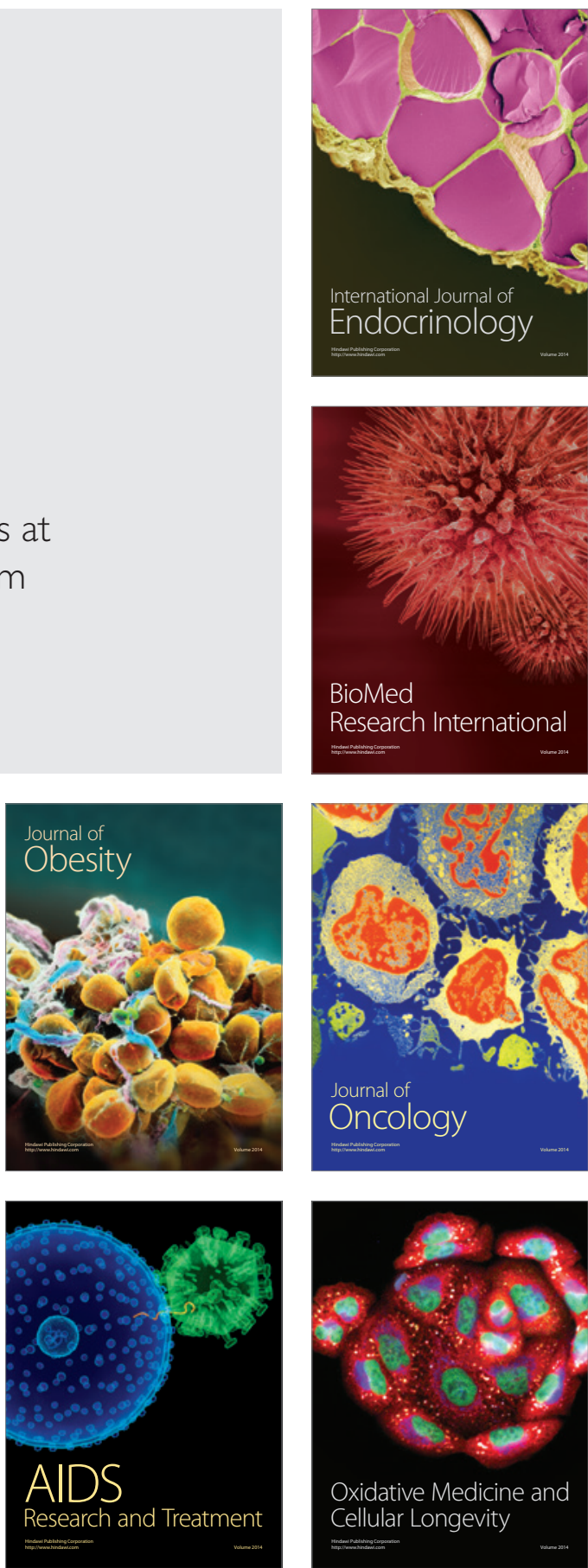